Yuriy Petrushenko, Doctor of Economic Sciences, Professor, Head of International Economic Relations Department, Sumy State University (Sumy, Ukraine)

Leonid Taraniuk, Doctor of Economic Sciences, Professor, Professor of International Economic Relations Department, Sumy State University (Sumy, Ukraine)

Hongzhou Qiu, Experimenter of School of Artificial Intelligence, Henan Institute of Science and Technology (Luoyang, China)

Karina Taraniuk, Candidate of Sciences in Economics (Ph.D.), Senior Lecturer, Department of Management, Sumy State University (Sumy, Ukraine)

\title{
ANALYSIS ON APPLICATION AND CONTRIBUTION OF INTERNET OF THINGS TO DEVELOPMENT OF LOGISTICS ENTERPRISES: EXPERIENCE OF CHINA
}

\begin{abstract}
The introduction of digital technologies in the work of logistics companies is relevant, because it forms the basis for automation of business processes of firms. The main problems of logistics activities of enterprises include: outdated standards and technologies for managing logistics processes in China. Therefore, there is a need to introduce the Internet of Things in order to improve the quality of services of enterprises. A comparative analysis of the use of the Internet of Things in the work of logistics in Chinese companies. Positive and negative factors of influence on the digitalization of the processes of Chinese logistics companies have been formed. The organizational and economic support for the interaction of stakeholders with Chinese logistics companies with the use of the Internet of Things has been improved. The introduction of the Internet of Things is necessary for the formation of progressive trajectories for the development of China's logistics companies.
\end{abstract}

Keywords: estimation, digital technologies, Internet of Things, logistic enterprises, international development, efficiency, communications

Introduction. The Internet of Things is called the third wave of the world information industry after the computer and the Internet. In the vision of the Internet of Things, EPC codes stored in RFID tags are automatically collected to a central information system through a wireless data communication network to realize the identification of items. At present, the United States, the European Union, China and other countries are investing heavily in in-depth research and exploration of the Internet of Things. The construction of the huge Internet of Things can not only stimulate new investment, but also improve the efficiency of 
the original economic operation, with a dual effect. The Internet of Things is widely used. As one of the national "ten industrial revitalization plans", logistics industry is an important field. Modern logistics is "the advanced stage of the development of traditional logistics, based on the advanced information technology, which pays attention to service, personnel, technology, information and management of integrated systems. It is a modern mode of production, operation and management, the combination of information technology in the field of logistics makes the social logistics and production logistics organically unified, starting from the procurement logistics, production logistics to distribution logistics. The implementation of modern logistics management often requires help of advanced technology, it will combine production, transportation, warehousing, distribution, loading and unloading, handling, and packaging and other logistics activities together in order to realize the logistics management automation, informatization, network and intelligent systems. This new type of integrated management, can reduce the total cost of logistics, to serve customers better [Xiaoying G. 2020, p.2].

\section{The impact of Internet of Things on modern logistics.}

\subsection{Promotion of the development of logistics informatization.}

The development of Internet of Things can promote the informatization, automation and integration of logistics infrastructure. Internet of Things technology was applied to the trays, shelves, the recognition of logistics infrastructure, such as vehicles, container loading and unloading port inside the warehouse, transport vehicles, transport equipment, logistics level install the Internet of things such as reading and writing device, not only can automatically collect the Internet of things in the links of logistics delivery information, automatic completion of inbound and outbound goods and inventory, and also can realize transparent management of inventory of the item. The application of Internet of Things technology to logistics transportation equipment and transportation facilities can greatly improve the level of informatization and automation of logistics infrastructure. The informatization, automation and integration of logistics management and process monitoring can not only improve enterprises' logistics efficiency and control enterprises' logistics costs, but also greatly improve the informatization level of related logistics enterprises on the whole and drive the rapid development of the whole logistics industry. 


\subsection{Optimization of the flow of logistics management.}

There are many business links in the logistics chain, including packaging, handling, transportation, procurement, loading and unloading, storage and other links, as well as distribution, circulation and processing, service and sales. All these links are indispensable, and they complement each other and restrict each other. The business process of logistics is very complex and runs a variety of data flows at the same time, including information flow, business flow, capital flow and logistics. In order to make place to its maximum economic and social benefits. The enterprise must understand and recognize the state of change and flow direction of the four flows in the whole logistics link in real time and accurately, and make the four parties keep the same pace and cooperate with each other in each link and process. However, in the process of practice, the position of the actual object changes, and the state of each link changes and loosens. When the entity changes in position and time, the information also changes constantly, which not only affects the availability of information, but also destroys the sharing of information, resulting in a high error rate. RFID technology can not only effectively solve the problem of data input of various business operations in logistics management, but also solve the problem of data output, and solve the problem of business process control and tracking [Man S. 2019, p. 24].

\subsection{Reduction of storage cost.}

The main purpose of modern logistics management is not only to reduce logistics costs but also to improve the level of logistics services. The literature shows that:

«At present, the labor cost and equipment cost of each link of logistics in China are far lower than those of developed countries, while the overall cost of the whole logistics process is much higher than that of developed countries, mainly because of the large inventory, resulting in high inventory cost. So you have to find ways to reduce inventory levels, which is a core part of modern logistics management». «Traditional logistics enterprises need to build large capacity of the warehouse, and modern logistics is to establish a «virtual warehouse», through the network system scattered around to connect the points belonging to different enterprise warehouses. The unified deployment and management, not only expands the radius of logistics services, but also widens the goods distribution space, improves enterprise organizational resources and speed, large size items management, high efficiency, and makes resource allocation reasonable. Compared with the traditional logistics enterprises, it has obvious advantages». Moreover, the warehouse management system based on Internet of Things technology eventually will be according to the number of the current customer orders 
and inventory including the triggering system for replenishment which will automatically collect information by wireless transmission uploaded to the logistics distribution center, and then through the Internet to the warehouse management system. The system according to the received data dynamically update data in the database, automatically complete information exchange and communication, so as to improve the ability of inventory management, reduce inventory levels and to reduce the warehouse cost [Kangwen Z., and. oth., 2019, p.11-13].

\subsection{Realization of real-time monitoring and real-time decision-making of the} whole logistics process.

The traditional logistics distribution process is composed of multiple business processes and multiple links, and each link requires human intervention and participation, which is too much interfered by human factors. If there is still a continuation of human involvement in the logistics of each distribution process, human error is inevitable. However, any link, any human error, will make the computer accurate number statistics, analysis cannot go on. Therefore, a key problem to realize modern logistics is to realize automation and networking from the peripheral nerve of any raw material procurement, production and transportation to the operation process of the whole system, which requires real-time monitoring and real-time decision-making for the whole process of logistics. When a requirement information is received at any end of the logistics system, the system must respond quickly, develop a detailed distribution plan, and communicate it to each link to get it to work. In order to reduce the cost, optimize the inventory structure, speed up the capital turnover, shorten the production cycle, and ensure the efficiency of modern production. Modern industrial production pursues «zero inventory» and «just in time». Therefore, in order to meet the requirements of modern industrial production, it is necessary to vigorously develop modern logistics, and the Internet of Things technology is an effective technical means to achieve modern logistics.

\subsection{Improvement of logistics efficiency and reduction of logistics costs.}

By integrating the functions of the logistics system and integrating the circulation channels and information resources on a large scale, Internet of Things technology can optimize the allocation of social resources, thus improving the circulation efficiency, market circulation environment and circulation speed. Through the synchronous integration of the Internet of Things and related enterprises in supply, production, logistics, demand and other processes, the inventory quantity of raw materials, semi-finished products and finished 
products in each link of the supply chain can be effectively controlled. It alleviates the uncertainty in supply and demand, effectively reduces the inventory and capital occupancy between upstream and downstream cooperative enterprises in the supply chain, and not only effectively improves the efficiency of the original system. And it also saves the management cost of supply chain. At the same time, the Internet of Things through RFID technology for identification and inspection, automatic goods inspection, with no need to unload and one by one count, simplifies the goods acceptance link and reduces the number of handling. Intelligent tracking of transportation means through the Internet of Things can timely acquire real-time information of transportation means, reduce the number of required transportation means and transportation personnel, and can avoid idleness of vehicles. Improvement of utilization ratio is carried out through The Internet of Things which will help reduce inventory costs and losses caused by theft, damage and loss of goods in transit [Songling Z., Jingyu C. 2020, p. 10].

\section{Literature review.}

The study of scientific literature contains an analysis of the introduction of Internet of Things tools in the development of logistics enterprises in China. Thus, the scientist Xiaoying G. in his work [Xiaoying 2020, p.1-4] explored the issues of advertising of logistics companies and their informatization through the use of big data analysis to plan and forecast logistics work with the customer in China. Scientist Man S. in [Man 2019, p. 24-27] analyzed the current situation of intellectual property in logistics work through the transformation of logistics and improvement of information technology for its implementation in Chinese enterprises. Economists Kangwen, Z., Zhanyu, L., Man W. [Kangwen, and. oth., 2019, p.11-13] studied the strategic aspects of science-intensive technologies and innovative development in increasing the value of China's logistics companies. Scientists Songling Z., Jingyu C. in [Songling, Jingyu 2020, p. 8-10] studied the development of logistics services through the promotion of information technology. Scientist Yijun M. [Yijun M. 2020, p. 4-6] studied the construction of an intelligent logistics ecosystem based on sustainable development. Researcher Kai S. [Kai S. 2020, p. 2-4] studied the development of strategic aspects of logistics companies in China using deep data analysis. Scientists Rui J., Weihua L., Siyu W., Wenfei W. in [Rui J., and. oth., 2020, p. 4-6] developed a model of intelligent logistics in the work of Chinese enterprises through the use of artificial intelligence. In general, we can note the lack of research on the implementation of the Internet of Things in 
the logistics of Chinese companies, so the authors draw attention to the need for such analyses.

\section{Analysis of existing problems of application and contribution of internet of} things to development of logistics enterprises in China.

The application of modern logistics and the Internet of Things is a rather complex and huge system engineering, which involves not only technology, but also business, economic, legal and social issues. Therefore, the development of modern logistics based on the Internet of Things is bound to have policies, laws, safety, standards and costs and other problems.

\subsection{Policy issues.}

The government is the decision-making department responsible for making political and economic policies, and policy is the key factor determining modern logistics standardization and Internet of Things system. The standardization of modern logistics and the construction of the Internet of Things are both cross-border business activities. Therefore, a global e-commerce rules must be established to ensure the smooth development of e-commerce and related projects. Whether at home or abroad, modern logistics standardization and the development of the Internet of things system are still in the initial state, pursuing exploration of the role of governments in e-commerce. Our government must attach great importance to the establishment of modern logistics standards and the construction of the Internet of things system [Yijun 2020, p.6].

\subsection{Legal issues.}

Law is one of the key factors that determine the development of modern logistics. The normal operation of business activities needs to rely on laws to maintain and regulate any illegal activities which will be subject to the corresponding legal sanctions. Modern logistics and traditional logistics activities are very different, buyers and sellers may have national differences, a variety of legal disputes related to e-commerce will appear, dispute resolution needs to have a mature, unified legal system to adjudicate For the healthy development of e-commerce and modern logistics application, it is necessary to study and formulate corresponding laws and regulations to provide a transparent and harmonious legal environment for e-commerce. 


\subsection{Safety issues.}

Security is one of the important reasons that restrict the development of e-commerce and modern logistics. The application prospect of e-commerce and modern logistics is very attractive, but many merchants still have doubts about whether or not to adopt it. In traditional business activities, the transaction parties meet face to face, the security of the transaction is easy to be guaranteed, and it is easy to establish the trust relationship between the transaction parties. However, in the process of e-commerce and modern logistics application, businesses, consumers and Banks are connected through network communication. They may not know each other, and they complete shopping and payment and other business activities through the network. It can be seen that all parties of e-commerce and modern logistics are facing certain security threats, and effective means are needed to ensure the smooth application of e-commerce and modern logistics. Therefore, the issue of how to use security technology to create a secure e-commerce and modern logistics application environment, the majority of businesses and consumers are very concerned about. In the application process of e-commerce and modern logistics, business secrets and personal privacy of enterprises should never be disclosed. In the increasingly fierce market competition environment, how to ensure the security of trade secrets and personal privacy is particularly important [Kai 2020, p. 3].

\subsection{Standard issues.}

A new industry is to be developed. Standardization is a necessary stage. If a unified standard cannot be formed, it will limit the development of the whole industry. Standards are the basis of information release and transmission. It is the necessary guarantee of information consistency on the network. At present, the Internet of Things including RFID has not formed a unified global standard. However, with the large-scale application of RFID technology in the global logistics industry, the industry has been widely recognized to develop a unified RFID standard. E-commerce and modern logistics application standards involve quite a lot of content, including basic standards, safety standards, operating standards, and RFID standards [Rui, and. oth., 2020, p. 4-6].

\subsection{Cost.}

In order to realize the Internet of Things, the Internet of people, the Internet of things and the Internet of people and things, the first thing is to identify the people or things that need to be connected to the network. RFID technology is an important branch of automatic identification technology, so a large number of RFID systems are bound to be used in the 
logistics application system based on the Internet of Things. At present, the cost of RFID system, whether a reader, an electronic tag or antenna, is relatively high, and high-price RFID tags are not suitable for low-price products in general. In addition, the construction of RFID system and training manpower also need to invest a lot of money. The application cost of Internet of Things technology not only includes the construction cost of RFID system, but also includes the construction of computer communication equipment, receiving equipment, data processing platform, system integration and other integrated systems. This is for the logistics industry with low profit margin difficult to bear [Rui, and. oth., 2020, p. 4-6].

Positive and negative factors of influence on the digitalization of the processes of Chinese logistics companies have been formed.

The negative factors include:

- information backwardness of Chinese logistics companies operating in district centers and remote provinces of China;

- low level of information culture among customers living primarily in rural areas for logistics products of Chinese companies;

- low level of information support and development of information technologies at enterprises in many provinces of China.

The positive factors include:

- high level of informatization of the society of urban territories and large cities of China;

- development of electronic business trading platforms, which contain modern information technologies of communication between Chinese logistics companies to customers of their products;

- high level of competition development among Chinese logistics companies, which stimulates the rapid development of the Internet of Things in the logistics of companies.

Attention should also be paid to improving the organizational and economic support of stakeholders' interaction with China's logistics companies using the Internet of Things. To this provision, the authors propose to add the development of an information office to support various stakeholders who are interested in establishing effective work between enterprises, customers, the Chinese government and investors. The main functions of this office should be: informatization of stakeholders, development of artificial network technologies, formation of an electronic register between logistics companies, their customers and other stakeholders, implementation of consulting work using Big Data analysis, which will increase the efficiency 
of communication between participants in the logistics process of Internet of Things and Big Data Tools.

\section{Conclusion.}

The rapid development of Internet technology and in-depth applications, will greatly promote the development of modern logistics industry, we must firmly grasp the good development opportunity, Internet of things to build a logistics flow, convenient and quick, economic and reasonable, humane wisdom logistics service system, and constantly improve the level of our country's logistics industry technology, a driving force for the development of the logistics to provide more. To the directions of further research it is necessary to add the formation of an economic model of using the Internet of Things in the work of logistics companies in order to form the dependence of various macro- and microeconomic indicators of logistics companies and their impact on economic efficiency of the company as a whole.

\section{References}

1. Kai, S. (2020). Research on the Development Strategy of Intelligent Logistics in the Context of Big Data. Logistics Technology and Market, no. 2, pp. 2-4.

2. Kangwen, Z., Zhanyu, L. and Man, W. (2019). Strategies of Scientific and Technological Innovation driving the high-quality development of China's intelligent Logistics industry. Innovative Technology, no.11, pp. 11-13

3. Man, S. (2019). Analysis on the Current Situation of Intelligent Logistics promoting the Transformation and Upgrading of logistics Industry, Western Logistics, no. 24, pp. 24-27.

4. Rui, J., Weihua, L., Siyu, W. and Wenfei, W. (2020). Development Path and Model of Intelligent Logistics. Logistics Technology, no. 4, pp. 4-6.

5. Songling, Z. and Jingyu, C. (2020). Exploring the Path of developing intelligent Logistics. People's Forum, no. 8, pp. 8-10.

6. Xiaoying, G. (2020). Discussion on China's Promotion of Logistics Informatization in the Era of Big Data. Modern Business and Trade Industry, no. 1, pp.1-4.

7. Yijun, M. (2020). How to build intelligent logistics Ecosystem based on sustainable Development. China Logistics and Procurement, no. 4, pp. 4-6. 